\title{
Avulsion Fracture of the Tuberosity of the Calcaneus: A Case Report
}

\author{
Hicham Ait Benali, Hamza Madani", Jaouad Yasser, Mohamed Asbai, Mohammed Shimi
}

Department of Orthopedics and Traumatology, University Hospital Center of Tangier, Faculty of Medicine and Pharmacy of Tangier, Abdelmalek Essaâdi University, Tangier, Morocco

DOI: $10.36347 /$ sjmcr.2020.v08i08.010

| Received: 27.07.2020 | Accepted: 03.08.2020 | Published: 14.08.2020

*Corresponding author: Hamza Madani

\section{Abstract}

The avulsion fracture of the calcaneal tuberosity are rare. They correspond to a disinsertion of the calcaneal tendon and must necessarily be repaired surgically. The mechanisms of injury are forced plantar flexion or abrupt dorsiflexion. In this article, we report a rare case of avulsion fracture of the calcaneal tuberosity in a 35-year-old man. We discuss the clinical and therapeutic aspects for this lesion. Surgical treatment was realized with Percutaneous Cannulated Screw Fixation and equinus short leg cast immobilization.

Keywords: Avulsion, Fracture, Calcaneus, Tuberosity, Screw.

Copyright @ 2020: This is an open-access article distributed under the terms of the Creative Commons Attribution license which permits unrestricted use, distribution, and reproduction in any medium for non-commercial use (NonCommercial, or CC-BY-NC) provided the original author and source are credited.

\section{INTRODUCTION}

Avulsion fractures of the calcaneal tuberosity are rare extra-articular injuries, which usually occur because of an indirect mechanism of forced ankle dorsiflexion. Their treatment is habitually surgical [1].

In this paper, we report a unique case of avulsion fractures of the calcaneal tuberosity. We discuss their mechanism of occurrence, different types and therapeutic characteristics.

\section{CASE Report}

An 35 -year-old man with no particular pathological history admitted to the emergency department for closed ankle trauma following a fall from a high height in forced dorsiflexion, causing pain with total functional impotence of the right foot.

The clinical evaluation found swelling and bruising of the ankle (Figure-1), no skin opening, an inability to actively plantar flexion of the right foot and a positive Thompson sign.

X-ray foot was taken, showed a type II avulsion fracture of the calcaneal tuberosity according to Beavis classification (Figure-2).

The patient was admitted to the operating room; under spinal anesthesia, he was placed in prone position with a support under foot (Figure-3). Surgical treatment, in emergency, consisted on a closed reduction under the control of an image intensifier and a percutaneous fixation by two cannulated screws (Figure-4).

Following the operation, the right foot was immobilized in an equinus short leg cast for 6 weeks after the plaster has been removed; the patient has benefited from functional rehabilitation for analgesic purpose and recovery of the joint amplitudes. 


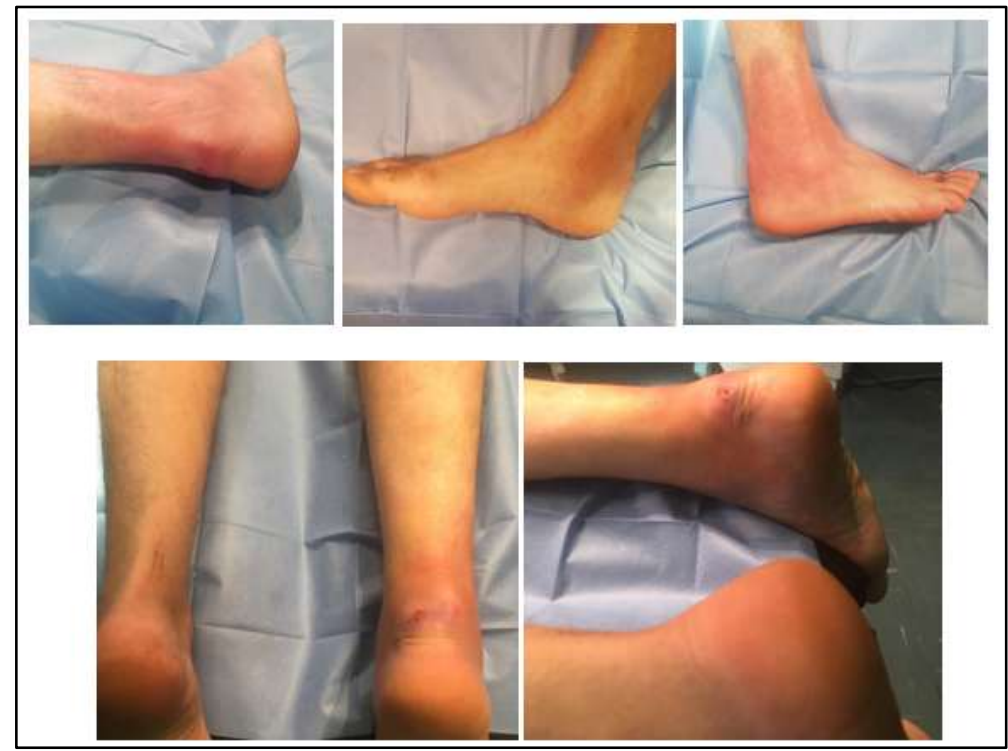

Fig-1: Clinical photos showed the skin impinged by the fragment

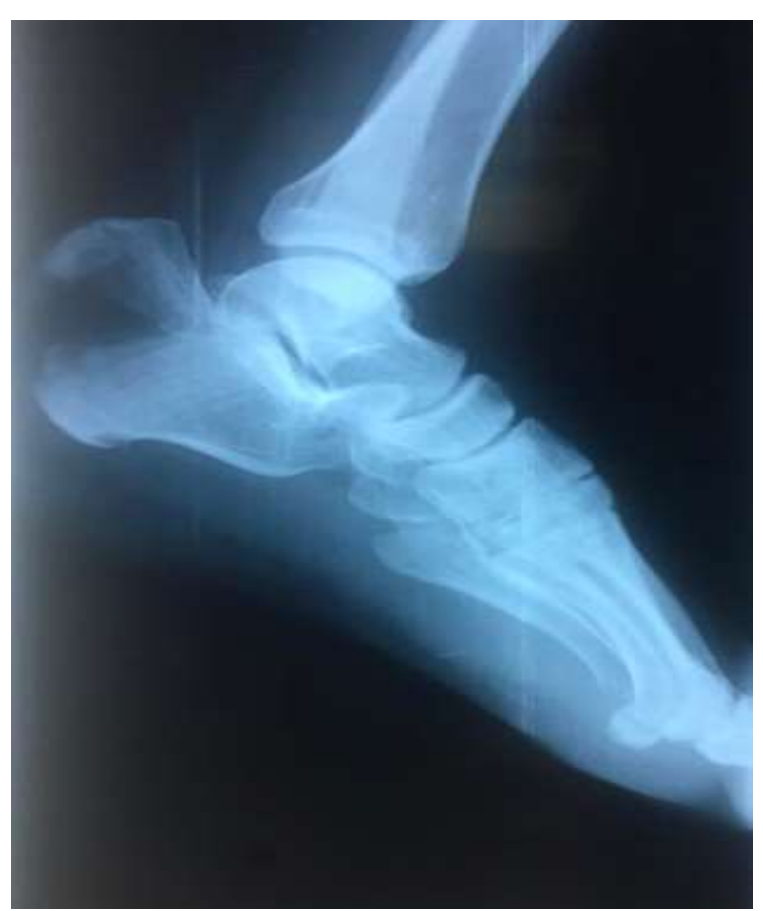

Fig-2: $\mathrm{X}$ rays showed the extra-articular avulsion fracture of the posterosuperior tuberosity of the calcaneus (type II)
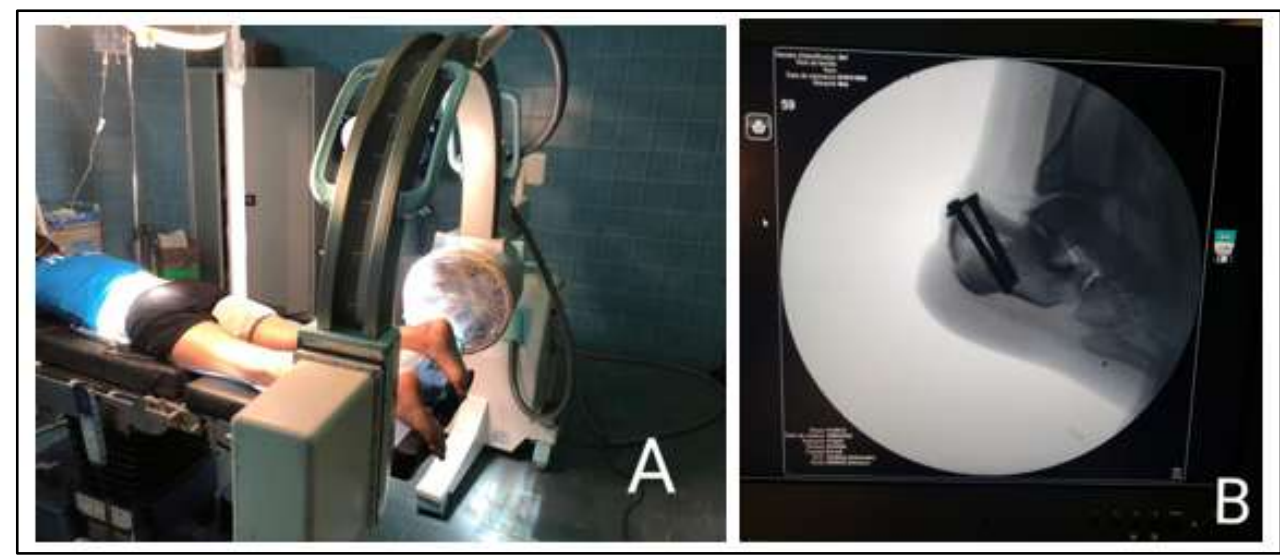

Fig-3: (A) the patient is placed in the prone position. (B) Reduction under the control of an image intensifier and a percutaneous fixation by two cannulated screws 


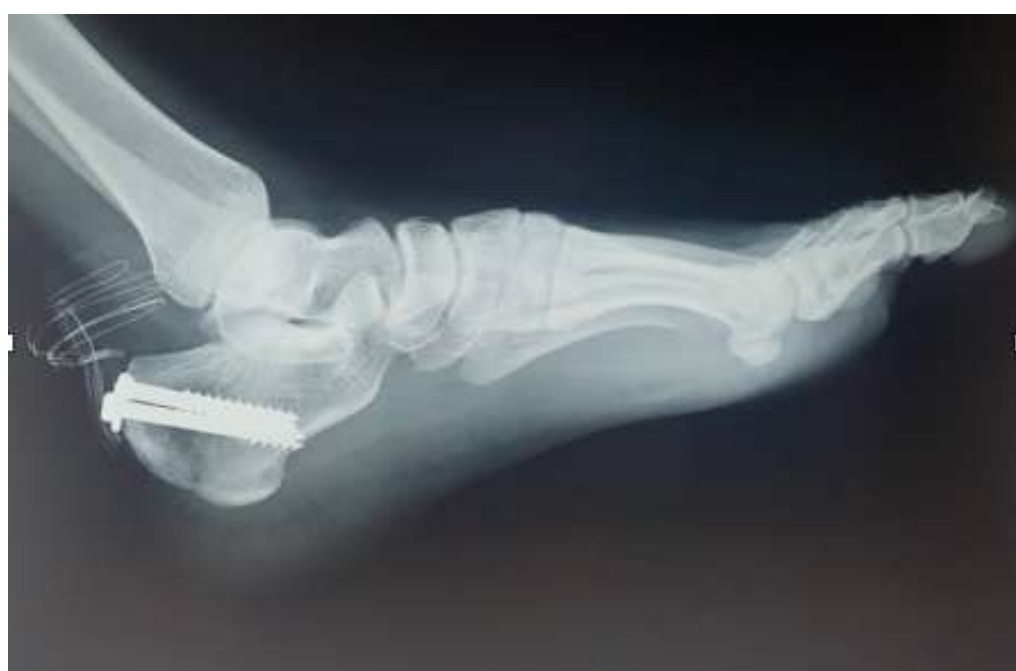

Fig-4: Ankle control profile x-ray. Screwing of the calcaneal tuberosity fracture with two cancellous screws

\section{DISCUSSION}

The avulsion fracture of the calcaneal tuberosity are uncommon [1]. Nevertheless, the incidence of their isolated form is low; it reaches only $1.3 \%$ to $2.7 \%$ of all calcaneal fractures [2].

The most common mechanism of avulsion fractures of the calcaneal tuberosity is forced dorsiflexion of the ankle, sometimes it can be due to a violent contraction of the sural triceps, but rarely due to direct trauma of the hindfoot [3].

The osteoporotic origin has been suggested in many studies as a reason of avulsion fractures of the calcaneal tuberosity. These fractures have also been observed with increased frequency in diabetic patients due to insufficiency fractures associated with peripheral neuropathy [4]. However, these pathologies cannot explain the ruptures detected in young male patients, as is the case in our observation.

Avulsion fracture of the posterosuperior tuberosity of the calcaneus can be classified into two types depending on the location of the calcaneal tendon insertion [5].

Beavis et al., proposed a type I to III classification scheme for avulsion fractures of the calcaneal tuberosity. Lee et al., modified this specific study through the addition of another avulsion type IV fracture. The Type I fracture is a "simple extra-articular avulsion" fracture. Type II is the "beak" fracture in which there is an oblique fracture line running posterior from just behind Bohler's angle. Type III is rare; it is the infrabursal avulsed fracture by superficial fibers from the middle third of the posterior tuberosity. In the type IV fracture there is the "beak", but a small triangular fragment is separated by deep fibers only from the upper border of the tuberosity [4-6].
The treatment depends on the age, the functional request of the patient and the degree of displacement of the fragment [7], the non-surgical treatment can be done by closed reduction followed by immobilization with long leg cast, the ankle in slight plantar flexion. Reduction is obtained by simultaneous flexion of the knee and ankle, associated with direct pressure on the fragment moved. The main problems of this type of treatment are secondary displacement, strength's reduction of plantar flexion and more rarely pseudarthrosis. That is why many authors recommend a surgical treatment $[8,9]$.

Surgical treatment is indicated for displaced fractures of the calcaneal tuberosity, cutaneous decompression when displaced fragment seems to increase the risk of necrosis. This risk must be early recognized.

Open fracture is a surgical emergency. Treatment should include debridement of the wound, reduction and stabilization of the fracture and tensionfree skin suturing. Percutaneous or open reduction of the avulsion fracture of the posterosuperior tuberosity of the calcaneus together with lag screw fixation and equinus short leg cast immobilization can provide good results without skin necrosis [5].

Screwing is the most used method in simple avulsion fractures. However, the use of a plate may be necessary in large fragments.

Transosseous suture anchor fixation of an osteoporotic avulsion fracture of the calcaneal tuberosity seems to provide better and stronger fixation than that using lag screws [10].

In this case report, a closed reduction with percutaneous cannulated screw could be obtained, allowing a satisfactory result both anatomical and functional. Skin complications due to delayed treatment have also been reported in the literature [11]. 


\section{Conclusion}

The avulsion fracture of the calcaneal tuberosity is a rare entity. Reduction and stabilization are to be performed in emergency. The treatment is mainly surgical by screwing. The evolution is especially marked by the risk of occurrence of skin necrosis.

\section{REFERENCES}

1. Abou-Ali HA, Elhyaoui H, Rafaoui A, Rafai M, Garch A. Fracture avulsion de la tubérosité calcanéenne: à propos de deux cas. Médecine et Chirurgie du Pied. 2016 Dec 1;32(4):93-6.

2. Yu GR, Pang QJ, Yu X, Chen DW, Yang YF, Li B, Zhou JQ. Surgical management for avulsion fracture of the calcaneal tuberosity. Orthopaedic surgery. 2013 Aug;5(3):196-202.

3. Louaste J, Zejjari H, Chkoura M, Rachid K. Fracture-avulsion de la tubérosité calcanéenne: à propos d'un cas. JAMA. 1963;184(12):920-3.

4. Lee SM, Huh SW, Chung JW, Kim DW, Kim YJ, Rhee SK. Avulsion fracture of the calcaneal tuberosity: classification and its characteristics. Clinics in orthopedic surgery. 2012 Jun 1;4(2):1348.
5. Lui TH. Avulsion fracture of the posterosuperior tuberosity of the calcaneus managed with lag screw fixation. Foot and Ankle Surgery. 2018 Feb 1;24(1):45-8.

6. Beavis RC, Rourke K, Court-Brown C. Avulsion fracture of the calcaneal tuberosity: a case report and literature review. Foot \& ankle international. 2008 Aug;29(8):863-6.

7. Idrissi KK, Galiua F. Fracture avulsion du tendon calcanéen (à propos d'un cas). Médecine et chirurgie du pied. 2010 Mar 1;26(1):21-3

8. Robb CA, Davies MB. A new technique for fixation of calcaneal tuberosity avulsion fractures. Foot and ankle surgery. 2003 Jan 1;9(4):221-4.

9. Richmond JC, Donaldson WR, Fu F, Harner CD. Modification of the Bankart reconstruction with a suture anchor: report of a new technique. The American journal of sports medicine. 1991 Jul;19(4):343-6.

10. Rauer T, Twerenbold R, Flückiger R, Neuhaus V. Avulsion fracture of the calcaneal tuberosity: case report and literature review. The Journal of Foot and Ankle Surgery. 2018 Jan 1;57(1):191-5.

11. Rijal L, Sagar G, Adhikari D, Joshi KN. Calcaneal tuberosity avulsion fracture: an unusual variant. The Journal of foot and ankle surgery. 2012 Sep 1;51(5):666-8. 